\title{
Immunohistochemical detection of WT1 protein in a variety of cancer cells
}

Shin-ichi Nakatsuka ${ }^{1}$, Yusuke Oji ${ }^{2}$, Tetsuya Horiuchi ${ }^{3}$, Takayoshi Kanda ${ }^{4}$, Michio Kitagawa ${ }^{5}$, Tamotsu Takeuchi ${ }^{6}$, Kiyoshi Kawano ${ }^{7}$, Yuko Kuwae ${ }^{8}$, Akira Yamauchi ${ }^{9}$, Meinoshin Okumura ${ }^{10}$, Yayoi Kitamura ${ }^{2}$, Yoshihiro Oka ${ }^{11}$, Ichiro Kawase $^{11}$, Haruo Sugiyama ${ }^{12}$ and Katsuyuki Aozasa ${ }^{13}$

${ }^{1}$ Department of Clinical Laboratory, National Hospital Organization Osaka Minami Medical Center, Kawachinagano, Osaka, Japan; ${ }^{2}$ Department of Biomedical Informatics, Osaka University Graduate School of Medicine, Suita, Osaka, Japan; ${ }^{3}$ Department of Surgery, National Hospital Organization Osaka Minami Medical Center, Kawachinagano, Osaka, Japan; ${ }^{4}$ Department of Gynecology, National Hospital Organization Osaka Minami Medical Center, Kawachinagano, Osaka, Japan; ${ }^{5}$ Department of Urology, National Hospital Organization Osaka Minami Medical Center, Kawachinagano, Osaka, Japan; ${ }^{6}$ Department of Pathology, Kochi Medical School, Kohasu, Oko-cho, Nankoku City, Kochi, Japan; ${ }^{7}$ Department of Pathology, Osaka Rosai Hospital, Sakai, Osaka, Japan; ${ }^{8}$ Department of Pathology, Osaka Medical Center and Research Institute of Maternal and Child Health, Izumi, Osaka, Japan; ${ }^{9}$ Department of Cell Regulation, Faculty of Medicine, Kagawa University, Miki-cho, Kida-gun, Kagawa, Japan; ${ }^{10}$ Department of Surgery, Osaka University Graduate School of Medicine, Suita, Osaka, Japan; ${ }^{11}$ Department of Molecular Medicine, Osaka University Graduate School of Medicine, Suita, Osaka, Japan; ${ }^{12}$ Department of Functional Diagnostic Science, Osaka University Graduate School of Medicine, Suita, Osaka, Japan and ${ }^{13}$ Department of Pathology, Osaka University Graduate School of Medicine, Suita, Osaka, Japan

WT1 was first identified as a tumor suppressor involved in the development of Wilms' tumor. Recently, oncogenic properties of WT1 have been demonstrated in various hematological malignancies and solid tumors. Because WT1 has been identified as a molecular target for cancer immunotherapy, immunohistochemical detection of WT1 in tumor cells has become an essential part of routine practice. In the present study, the expression of WT1 was examined in 494 cases of human cancers, including tumors of the gastrointestinal and pancreatobiliary system, urinary tract, male and female genital organs, breast, lung, brain, skin, soft tissues and bone by immunohistochemistry using polyclonal (C-19) and monoclonal (6F-H2) antibodies against WT1 protein. Staining for $\mathrm{C}-19$ and $6 \mathrm{~F}-\mathrm{H} 2$ was found in 35-100 and 5-88\% of the cases of each kind of tumor, respectively. WT1-positive tumors included tumor of the stomach, prostate, and biliary and urinary systems, and malignant melanomas. A majority of the positive cases showed diffuse or granular staining in the cytoplasm, whereas ovarian tumors and desmoplastic small round cell tumors frequently showed nuclear staining. Glioblastomas, some of soft tissue sarcomas, osteosarcomas, and malignant melanomas of the skin showed extremely strong cytoplasmic staining as compared with other tumors. Western blot analysis showed that WT1 protein was predominantly expressed in the cytoplasm of the tumor cells in two cases of lung adenocarcinoma, supporting the intracytoplasmic staining for WT1 using immunohistochemistry. Immunohistochemical detection with routinely processed histologic sections could provide meaningful information on the expression of WT1 in cancer cells.

Modern Pathology (2006) 19, 804-814. doi:10.1038/modpathol.3800588; published online 17 March 2006

Keywords: WT1; immunohistochemistry; overexpression; oncogenesis

Correspondence: Dr S-i Nakatsuka, MD, Department of Clinical Laboratory, National Hospital Organization Osaka Minami Medical Center, 2-1 Kidohigashi-maohi, Kawachinagano, Osaka 586-8521, Japan.

E-mail: nakatsuk@ommc-hp.jp

Received 14 November 2005; revised 21 February 2006; accepted 23 February 2006; published online 17 March 2006
The WT1 gene, identified as a tumor suppressor gene located at 11p13, is involved in the development of Wilms' tumor. ${ }^{1,2}$ Germline mutations of WT1 have been described in Denys-Drash ${ }^{3}$ and WAGR $^{4}$ syndromes, which predispose individuals to the development of Wilms' tumor. Somatic mutations $^{5}$ and loss of heterozygosity ${ }^{6}$ of WT1 can 
be detected in $10 \%$ of sporadic Wilms' tumors. The WT1 gene encodes a transcription factor with four DNA-binding zinc fingers at the $\mathrm{C}$ terminus. ${ }^{1,2,7}$ In vitro studies showed that WT1 suppresses or activates a number of genes, including those for PDGF-A chain, EGF receptor, CSF-1, IGF-II, IGF-I receptor, RAR- $\alpha, c-m y c, b c l-2$, and WT1 itself. ${ }^{7,8}$ In embryonic life, WT1 plays a critical role in the development of the genitourinary tract, spleen, and mesothelial structures. ${ }^{3,4,9}$ In normal adult tissue, it is expressed in mesothelium, glomerular podocytes and mesangial cells of the kidney, CD34-positive hematopoietic stem cells, Sertoli cells of the testis, stromal cells, surface epithelium and granulosa cells of the ovary, and myometrium and endometrial stromal cells of the uterus. ${ }^{7}$

The WT1 gene was originally recognized as a tumor suppressor gene, but evidence of the oncogenic properties of the gene has been accumulating. WT1 mRNA is overexpressed in several kinds of hematological malignancies, and quantitative detection of its expression could be useful for monitoring minimal residual disease in case of leukemia. ${ }^{10-12}$ Furthermore, recent studies showed the overexpression of WT1 mRNA in various kinds of solid tumors, ${ }^{13}$ the growth inhibition of WT1-expressing cells by WT1 antisense oligomers, ${ }^{13,14}$ and a correlation between a high level of WT1 and a poor prognosis in patients with certain kinds of tumors. $^{12,15}$ These findings suggest that WT1 plays an oncogenic rather than tumor-suppressive role in human cancers. In such cases, sequencing revealed an absence of mutations in the WT1 gene in tumors, therefore wild-type WT1 could be oncogenic.

Immunohistochemically, WT1 is detected in the nucleus of tumor cells of Wilms' tumor and mesothelioma; therefore, WT1 has traditionally been used as a diagnostic marker for these tumors. ${ }^{16-20}$ Recent reports showed that other types of cancers, such as ovarian serous cancers and rhabdomyosarcomas $^{17,19-21}$ also express WT1. However, immunohistochemical data on WT1 expression in other types of cancers are either lacking or conflicting. ${ }^{17,18,21-24}$ As for staining patterns, cytoplasmic staining has been regarded as nonspecific and not been counted as positive in most previous reports. Therefore, the cytoplasmic staining of WT1 had not been evaluated in most types of tumors until now. However, recent reports have shown evidence that WT1 is involved not only in transcriptional regulation in the nucleus but also in RNA metabolism and translational regulation in the cytoplasm. The binding of WT1 to splicing factors ${ }^{25}$ and murine IGF-II mRNA $^{26}$ in vitro was demonstrated. Furthermore, nucleocytoplasmic shuttling of WT1 and the association of WT1 with actively translating polysomes were reported. ${ }^{27}$ Therefore, aberrant cytoplasmic localization of WT1 might alter the properties of tumor cells through the expressional regulation of variable genes.

An appropriate evaluation of WT1 expression in tumor cells is important at present, because WT1 is now regarded as a molecular target of immunotherapy for various malignant tumors. The clinical trial of a WT1 peptide-based cancer immunotherapy is on-going: WT1 vaccination was safe in all cases and clearly effective against several kinds of malignancies. $^{28,29}$ In routine practice, immunohistochemical analysis for WT1 expression using routinely processed histologic sections is essential to judge the eligibility of a patient for this immunotherapy. The present study was conducted to examine the availability of the immunohistochemical detection of WT1 in various human cancer cells with the use of a polyclonal and/or monoclonal antibody. Because intracytoplasmic staining was the predominant pattern detected with immunohistochemistry, the subcellular distribution of WT1 protein was examined by Western blotting.

\section{Materials and methods}

\section{Specimens}

Formalin-fixed and paraffin-embedded tissues from 494 tumors were retrieved with informed consent from archive sources at Osaka University Hospital and affiliated hospitals. The histologic diagnosis of each tumor was confirmed on the hematoxylin and eosin-stained sections: there were 13 esophageal cancers, 52 gastric cancers, 53 colorectal cancers, 26 pancreatic cancers, 23 biliary cancers, 65 lung cancers, 25 prostate cancers, 15 renal cancers, 39 urothelial cancers, 32 breast cancers, 22 uterine

Table 1 Age and sex for each type of malignancy

\begin{tabular}{lccc}
\hline Tumor types & $\begin{array}{c}\text { Case } \\
\text { number }\end{array}$ & $\begin{array}{c}\text { Age } \\
\text { (median) }\end{array}$ & $\begin{array}{c}\text { Sex } \\
(M: F)\end{array}$ \\
\hline Gastrointestinal and pancreatobiliary tumors & \\
Esophageal cancer & 13 & $54-85(63)$ & 5.5 \\
Gastric cancer & 52 & $34-90(69)$ & 1.4 \\
Colorectal cancer & 53 & $43-81(58)$ & 2.1 \\
Pancreatic cancer & 26 & $50-79(65)$ & 0.9 \\
Biliary cancer & 23 & $41-86(70)$ & 1.5 \\
Lung cancer & 65 & $52-79(66)$ & 1.7
\end{tabular}

Urinary and male genital tumors Prostate cancer

Renal cancer

Urothelial cancer

25

15

39

$53-75(68)$

$45-77(61)$

53-90 (73.5)

2.3

Breast and female genital tumors

Breast cancer

Cervical cancer

Endometrial cancer

Ovarian cancer

Brain tumor

Soft tissue sarcoma

Osteosarcoma

Malignant melanoma (skin)

Total

$\begin{array}{ll}31-65(50.5) & - \\ 21-74(50) & - \\ 32-78(55) & - \\ 42-84(53.5) & - \\ & \\ 2-82(43.5) & 0.9 \\ 2-64(17) & 2.0 \\ 5-31(16) & 2.0 \\ 41-73(68) & 1.3\end{array}$

494 
cervical cancers, 24 uterine endometrial cancers, 33 ovarian cancers, 27 brain tumors, 6 osteosarcomas, 32 soft tissue sarcomas, and 7 malignant melanomas of the skin. The demographic features of these cases are listed in Table 1.

\section{Immunohistochemistry}

Anti-WT1 antibodies used were a rabbit polyclonal antibody (clone C-19; Santa Cruz Biotechnology, Santa Cruz, CA, USA) raised against the C terminus (amino acids 431-450) of WT1 protein and a mouse monoclonal antibody (clone 6F-H2; Dako cytomation, Carpinteria, CA, USA) against the $\mathrm{N}$ terminus amino acids (1-181). After dewaxing and rehydration, $3-\mu \mathrm{m}$-thick sections were subjected to heatinduced epitope retrieval by microwaving them for $15 \mathrm{~min}$ in $1 \mathrm{mM}$ citrate buffer (pH 6.0), followed by incubation with anti-WT1 antibody diluted 1:100 at $4^{\circ} \mathrm{C}$ overnight. For $6 \mathrm{~F}-\mathrm{H} 2$, a positive signal was detected using the ENVISION + kit (Dako cytomation). For C-19, after incubation with biotinylated anti-rabbit or anti-mouse secondary antibody, sections were treated with a $3 \% \quad \mathrm{H}_{2} \mathrm{O}_{2}$ solution to reduce endogenous peroxidase activity. Visualization was performed by a standard avidin-biotin complex method using a Vectastain ABC elite kit (Vector Labs., Burlingame, CA, USA). For malignant melanoma, a positive signal was detected by the alkaline phosphatase system using a ENVISION labeled polymer-AP kit (Dako cytomation). As positive controls, sections from Wilms' tumor or mesothelioma were stained in parallel.

\section{Subcellular Fractionation}

Cancerous tissues (approx. $0.5 \mathrm{ml}$ ) were obtained from two patients with lung adenocarcinoma with informed consent. After a wash with PBS, the tissues were cut into small pieces and homogenized in $9 \mathrm{ml}$ of $0.25 \mathrm{M}$ sucrose using a Potter-Elvehjem homogenizer. The suspension was filtered with gauze and centrifuged in microcentrifuge tubes at 3300 r.p.m. for $10 \mathrm{~min}$ at $4^{\circ} \mathrm{C}$. The pellet was solved in $240 \mu \mathrm{l}$ of SDS sample buffer and stored as a nuclear fraction. The supernatant was centrifuged at 15000 r.p.m. for $10 \mathrm{~min}$ at $4^{\circ} \mathrm{C}$. The proteins in the supernatant were precipitated with acetone, solved in $240 \mu \mathrm{l}$ of SDS sample buffer, and stored as a cytoplasmic fraction.

\section{Western Blot Analysis}

Nuclear and cytoplasmic proteins from the cancerous tissues were loaded onto each well of the gel, separated by SDS-PAGE, and transferred onto an Immobilon polyvinylidene difluoride membrane (Millipore Corp., Bedford, MA, USA). After the blocking of nonspecific binding, the membrane was immunoblotted with the anti-WT1 mouse monoclonal antibody $6 \mathrm{~F}-\mathrm{H} 2$, anti-lamin $\mathrm{B}$ goat polyclonal antibody, or anti- $\alpha$-tubulin mouse monoclonal antibody (Santa Cruz Biotechnology), followed by incubation with the appropriate secondary antibody conjugated with alkaline phosphatase. Antibody binding was detected using a BCIP/NBT kit (Nacalai Tesque, Kyoto, Japan).

\section{Statistical Analysis}

Statistical analyses of the differences in positive rates for WT1 immunostaining among subtypes and grades of each tumor were performed with Fisher's exact probability test.

\section{Results}

In the positive controls, Wilms' tumor and mesothelioma, immunohistochemistry with either C-19 or $6 \mathrm{~F}-\mathrm{H} 2$ showed positive staining in the nucleus and/ or cytoplasm of the tumor cells (Figure 1). The
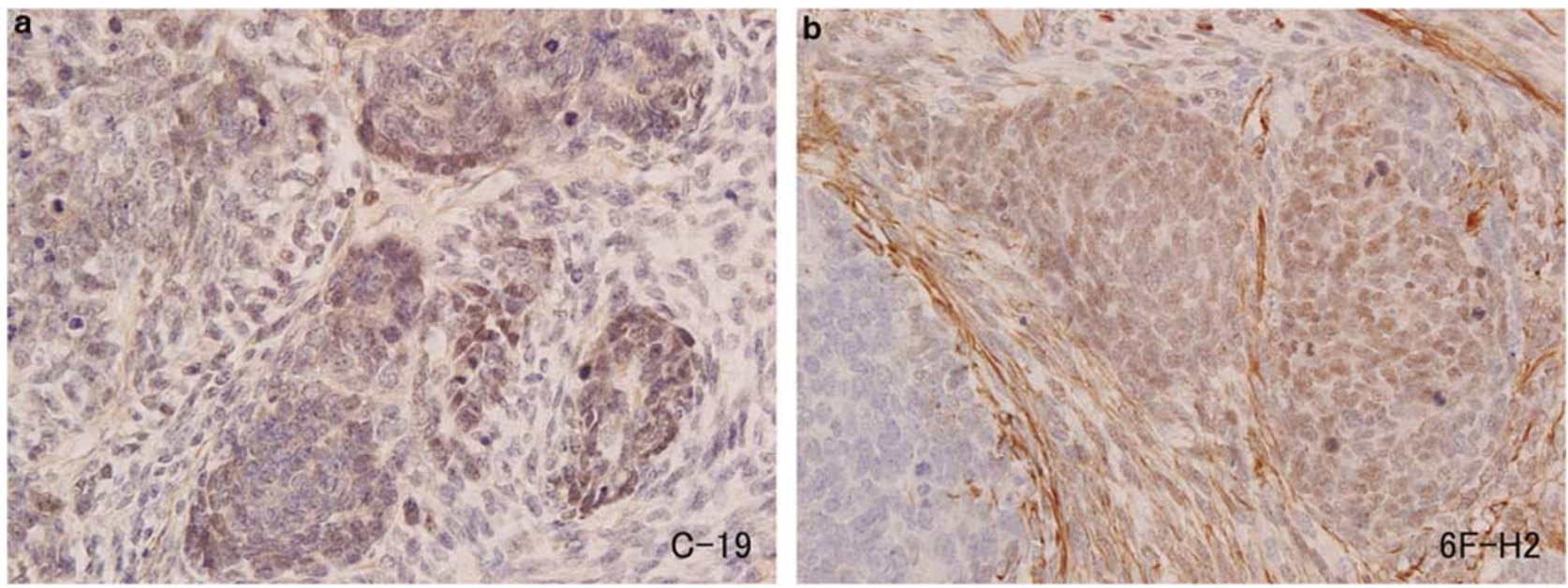

Figure 1 Immunohistochemical detection of WT1 in Wilms' tumor with C-19 (a) and 6F-H2 (b). Epithelial and mesenchymal components showed nuclear and/or cytoplasmic immunoreactivity for either antibody. Original magnification $\times 400$. 
Table 2 Results of immunohistochemistry for WT1 according to tumor type

\begin{tabular}{|c|c|c|c|c|}
\hline \multirow{2}{*}{ Tumor types } & \multicolumn{2}{|c|}{ Polyclonal (C-19) } & \multicolumn{2}{|c|}{ Monoclonal (6F-H2) } \\
\hline & No. of positive cases & Ratio (\%) & No. of positive cases & Ratio (\%) \\
\hline Esophageal cancer & $\mathbf{9} / \mathbf{1 3}$ & 69 & $5 / 11$ & 45 \\
\hline \multicolumn{5}{|l|}{ Squamous cell carcinoma } \\
\hline Moderately differentiated & $7 / 11$ & 64 & $4 / 9$ & 44 \\
\hline Poorly differentiated & $2 / 2$ & 100 & $1 / 2$ & 50 \\
\hline Gastric cancer & $17 / 32[1]^{\mathrm{a}}$ & $\mathbf{5 3}$ & $21 / 50[1]$ & 42 \\
\hline \multicolumn{5}{|l|}{ Adenocarcinoma } \\
\hline Well to moderately differentiated & $7 / 14$ & 50 & $15 / 23$ & $65]^{*}$ \\
\hline Poorly differentiated & $10 / 18[1]$ & 56 & $5 / 24[1]$ & $21]$ \\
\hline Mucinous adenocarcinoma & & & $1 / 3$ & 33 \\
\hline Colorectal cancer & $33 / 48$ & 69 & $31 / 45$ & 69 \\
\hline \multicolumn{5}{|l|}{ Adenocarcinoma } \\
\hline Well to moderately differentiated & $27 / 41$ & 66 & $28 / 37$ & $767^{* *}$ \\
\hline Poorly differentiated & $6 / 7$ & 86 & $3 / 8$ & $38\rfloor$ \\
\hline Pancreatic cancer & $7 / 20$ & 35 & $11 / 17$ & 65 \\
\hline \multicolumn{5}{|l|}{ Ductal adenocarcinoma } \\
\hline Well to moderately differentiated & $7 / 16$ & 44 & $10 / 14$ & 71 \\
\hline Poorly differentiated & $0 / 1$ & 0 & $0 / 1$ & 0 \\
\hline Mucinous noncystic carcinoma & $0 / 2$ & 0 & $1 / 1$ & 100 \\
\hline Islet cell tumor & $0 / 1$ & 0 & $0 / 1$ & 0 \\
\hline Biliary cancer & $12 / 15$ & 80 & $15 / 22$ & 68 \\
\hline \multicolumn{5}{|l|}{ Adenocarcinoma } \\
\hline Well to moderately differentiated & $9 / 11$ & 82 & $12 / 17$ & 71 \\
\hline Poorly differentiated & $3 / 4$ & 75 & $3 / 5$ & 60 \\
\hline Lung cancer & $47 / 65[1]$ & 72 & $13 / 43[1]$ & 30 \\
\hline \multicolumn{5}{|l|}{ Adenocarcinoma } \\
\hline Well differentiated & $8 / 9$ & 89 & $3 / 6$ & 50 \\
\hline Moderately differentiated & $17 / 25$ & 68 & $6 / 17$ & 35 \\
\hline Poorly differentiated & $12 / 15[1]$ & 80 & $2 / 10[1]$ & 20 \\
\hline \multicolumn{5}{|l|}{ Squamous cell carcinoma } \\
\hline Well differentiated & $1 / 1$ & 100 & $0 / 1$ & 0 \\
\hline Moderately differentiated & $7 / 9$ & 78 & $2 / 4$ & 50 \\
\hline Small cell carcinoma & $1 / 3$ & 33 & $0 / 3$ & 0 \\
\hline Mucoepidermoid carcinoma & $0 / 2$ & 0 & $0 / 1$ & 0 \\
\hline Adenoid cystic carcinoma & $1 / 1$ & 100 & $0 / 1$ & 0 \\
\hline Prostate cancer & $8 / 15[1]$ & 53 & $6 / 24$ & 25 \\
\hline \multicolumn{5}{|l|}{ Adenocarcinoma } \\
\hline Well to moderately differentiated & $6 / 11$ & 55 & $4 / 15$ & 27 \\
\hline Poorly differentiated & $2 / 4$ & 50 & $2 / 9$ & 22 \\
\hline Renal cancer & $7 / 15$ & 47 & $5 / 14$ & 36 \\
\hline \multicolumn{5}{|l|}{ Clear cell carcinoma } \\
\hline Grade 1 & $4 / 8$ & 50 & $2 / 8$ & 25 \\
\hline Grade 2 & $2 / 4$ & 50 & $1 / 3$ & 33 \\
\hline Grade 3 & $1 / 1$ & 100 & $1 / 1$ & 100 \\
\hline Sarcomatous carcinoma & $0 / 1$ & 0 & $0 / 1$ & 0 \\
\hline Papillary carcinoma & $0 / 1$ & 0 & $1 / 1$ & 100 \\
\hline Urothelial cancer & 11/17 [3] & 65 & $13 / 39$ & 33 \\
\hline \multicolumn{5}{|l|}{ Urotheilal carcinoma } \\
\hline Grade 1+Grade 2 & $8 / 12[3]$ & 67 & $6 / 30$ & $20]^{*}$ \\
\hline Grade 3 & $3 / 5$ & 60 & $7 / 9$ & $78\rfloor$ \\
\hline Breast cancer & $24 / 32$ & 75 & $13 / 25[2]$ & 52 \\
\hline Intraductal carcinoma & $0 / 1$ & 0 & $0 / 1$ & 0 \\
\hline \multicolumn{5}{|l|}{ Invasive ductal carcinoma } \\
\hline Papillotubular type & $9 / 12$ & 75 & $7 / 11$ & 64 \\
\hline Solid tubular type & $6 / 8$ & 75 & $2 / 6$ & 33 \\
\hline Scirrhous type & $9 / 10$ & 90 & $4 / 6[2]$ & 67 \\
\hline Paget's disease & $0 / 1$ & 0 & $0 / 1$ & 0 \\
\hline
\end{tabular}


Table 2 Continued

\begin{tabular}{|c|c|c|c|c|}
\hline \multirow[t]{2}{*}{ Tumor types } & \multicolumn{2}{|c|}{ Polyclonal (C-19) } & \multicolumn{2}{|c|}{ Monoclonal (6F-H2) } \\
\hline & No. of positive cases & Ratio (\%) & No. of positive cases & Ratio (\%) \\
\hline \multicolumn{5}{|l|}{ Nuclear grade } \\
\hline Grade 1 & $1 / 1$ & 100 & $1 / 1[1]$ & 100 \\
\hline Grade 2 & $13 / 18$ & 72 & $7 / 13$ & 54 \\
\hline Grade 3 & $8 / 11$ & 73 & $5 / 9[1]$ & 56 \\
\hline \multicolumn{5}{|l|}{ Histologic grade } \\
\hline Grade 1 & $2 / 3$ & 67 & $2 / 3[1]$ & 67 \\
\hline Grade 2 & $14 / 18$ & 78 & $8 / 13$ & 62 \\
\hline Grade 3 & $6 / 9$ & 67 & $3 / 7[1]$ & 43 \\
\hline Cervical cancer & $9 / 16$ & 56 & $1 / 19$ & 5 \\
\hline Squamous cell carcinoma & $7 / 13$ & 54 & $1 / 18$ & 6 \\
\hline Adenocarcinoma & $2 / 3$ & 67 & $0 / 1$ & 0 \\
\hline Endometrial cancer & $7 / 14$ & $\mathbf{5 0}$ & $17 / 21[2]$ & 81 \\
\hline \multicolumn{5}{|l|}{ Endometrioid adenocarcinoma } \\
\hline Grade 1 & $4 / 6$ & 67 & $8 / 10$ & 80 \\
\hline Grade 2 & $0 / 1$ & 0 & $2 / 2[1]$ & 100 \\
\hline Grade 3 & $1 / 3$ & 33 & $3 / 4$ & 75 \\
\hline Serous adenocarcinoma & $1 / 3$ & 33 & $2 / 3[1]$ & 67 \\
\hline Carcinosarcoma & $1 / 1$ & 100 & $1 / 1$ & 100 \\
\hline Endometrial stromal tumor, high grade & & & $1 / 1$ & 100 \\
\hline Ovarian cancer & $18 / 29[4]$ & 62 & 21/32 [11] & 66 \\
\hline Serous adenocarcinoma & $11 / 17[2]$ & 65 & $12 / 17[7]$ & 71 \\
\hline Serous borderline tumor & $0 / 1$ & 0 & $0 / 1$ & 0 \\
\hline Mucinous adenocarcinoma & $1 / 2$ & 50 & $1 / 2$ & 50 \\
\hline Mucinous borderline tumor & & & $0 / 1$ & 0 \\
\hline Transitional cell carcinoma & $1 / 1$ & 100 & $1 / 1[1]$ & 100 \\
\hline Endometrioid adenocarcinoma & $0 / 2$ & 0 & $1 / 2$ & 50 \\
\hline Clear cell carcinoma & $3 / 4$ & 75 & $3 / 5$ & 60 \\
\hline Sex cord stromal cell tumor & $2 / 2[2]$ & 100 & $2 / 2[2]$ & 100 \\
\hline Carcinosarcoma & & & $1 / 1[1]^{\mathrm{b}}$ & 100 \\
\hline Brain tumor & $17 / 27$ & 63 & $23 / 26$ & 88 \\
\hline Astrocytoma & $3 / 3$ & 100 & $3 / 3$ & 100 \\
\hline Ependymoma & $0 / 1$ & 0 & $1 / 1$ & 100 \\
\hline Central neurocytoma & $1 / 1$ & 100 & $1 / 1$ & 100 \\
\hline Anaplastic astrocytoma & $3 / 4$ & 75 & $3 / 4$ & 75 \\
\hline Anaplastic oligodendroglioma & $1 / 1$ & 100 & $1 / 1$ & 100 \\
\hline Anaplastic ependymoma & $1 / 1$ & 100 & $1 / 1$ & 100 \\
\hline Glioblastoma & $8 / 15$ & 53 & $12 / 14$ & 86 \\
\hline Gliosarcoma & $0 / 1$ & 0 & $1 / 1$ & 100 \\
\hline \multicolumn{5}{|l|}{ Histological grade } \\
\hline Grade 2 & $4 / 5$ & 80 & $5 / 5$ & 100 \\
\hline Grade 3 & $5 / 6$ & 83 & $5 / 6$ & 83 \\
\hline Grade 4 & $8 / 16$ & 50 & $13 / 15$ & 87 \\
\hline Soft tissue sarcoma & $21 / 30[3]$ & 70 & $19 / 27[1]$ & 70 \\
\hline PNET/Ewing’s sarcoma & $5 / 8$ & 63 & $3 / 7$ & 43 \\
\hline Rhabdomyosarcoma & $3 / 7$ & 43 & $6 / 6$ & 100 \\
\hline Leiomyosarcoma & $4 / 4[1]$ & 100 & $2 / 3[1]$ & 67 \\
\hline Malignant fibrous histiocytoma & $2 / 3$ & 67 & $2 / 2$ & 100 \\
\hline Liposarcoma & $1 / 1$ & 100 & $1 / 2$ & 50 \\
\hline Malignant peripheral nerve sheath tumor & $1 / 1$ & 100 & $1 / 1$ & 100 \\
\hline Desmoplastic small round cell tumor & $2 / 2[2]$ & 100 & $1 / 2$ & 50 \\
\hline Angiosarcoma & $2 / 3$ & 67 & $2 / 3$ & 67 \\
\hline Clear cell sarcoma & $1 / 1$ & 100 & $1 / 1$ & 100 \\
\hline Osteosarcoma & $6 / 6[1]$ & 100 & $3 / 6$ & 50 \\
\hline Malignant melanoma (skin) & $4 / 7$ & 57 & $6 / 7$ & 86 \\
\hline
\end{tabular}

${ }^{\mathrm{a}}$ Number of cases showing nuclear staining of tumor cells is shown in square brackets.

${ }^{b}$ Nuclear staining was found in the epithelial element and cytoplasmic staining in the mesenchymal element.

${ }^{\mathrm{C}} \mathrm{PNET}$, primitive neuroectodermal tumor.

${ }^{*} P<0.01 ;{ }^{*} P<0.05$.

Bold values indicate subtotal number of each type of tumor. 
vascular endothelium and peripheral nerve fibers in the sections also showed cytoplasmic staining; therefore, the positive staining of these cells could be used as an inner control.

Results of staining are summarized in Table 2. Immunohistochemistry with $\mathrm{C}-19$ revealed that substantial proportion (35-100\%) of the cases of each kind of cancer showed a positive reaction. In
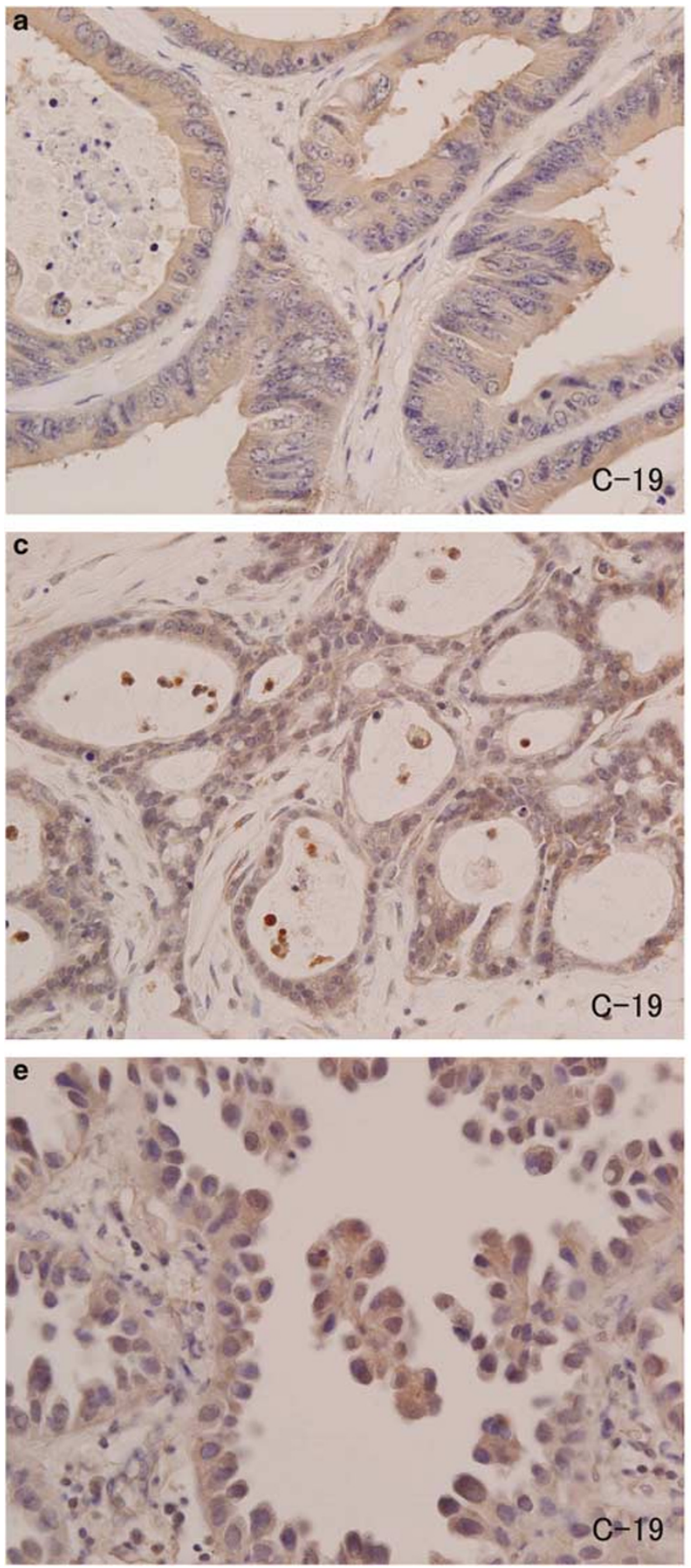

contrast, positive rates for $6 \mathrm{~F}-\mathrm{H} 2$ varied with the type of tumor; relatively high rates in cases of rhabdomyosarcoma (100\%), brain tumors (88\%), malignant melanoma of the skin $(86 \%)$, uterine endometrial cancer $(81 \%)$, and ovarian serous adenocarcinoma (71\%). A majority of positive cases showed a diffuse or granular staining in the cytoplasm of the tumor cells (Figure 2). A majority
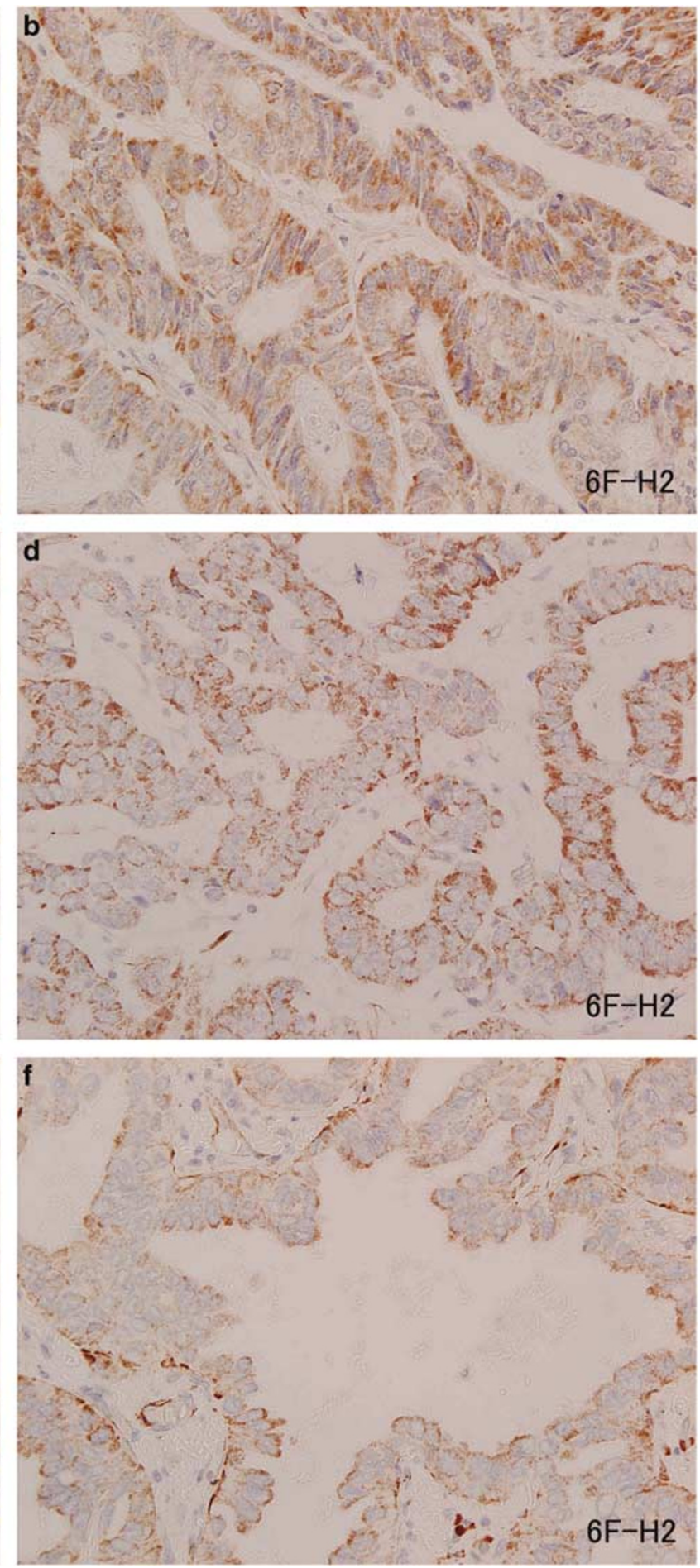

Figure 2 Colon cancer $(\mathbf{a}, \mathbf{b})$, uterine endometrioid cancer $(\mathbf{c}, \mathbf{d})$, and lung adenocarcinoma $(\mathbf{e}, \mathbf{f})$ showed diffuse cytoplasmic staining for C-19 (a, c, e), and granular cytoplasmic staining (b, d, f) for $6 \mathrm{~F}-\mathrm{H} 2$. Original magnification $\times 400$. 

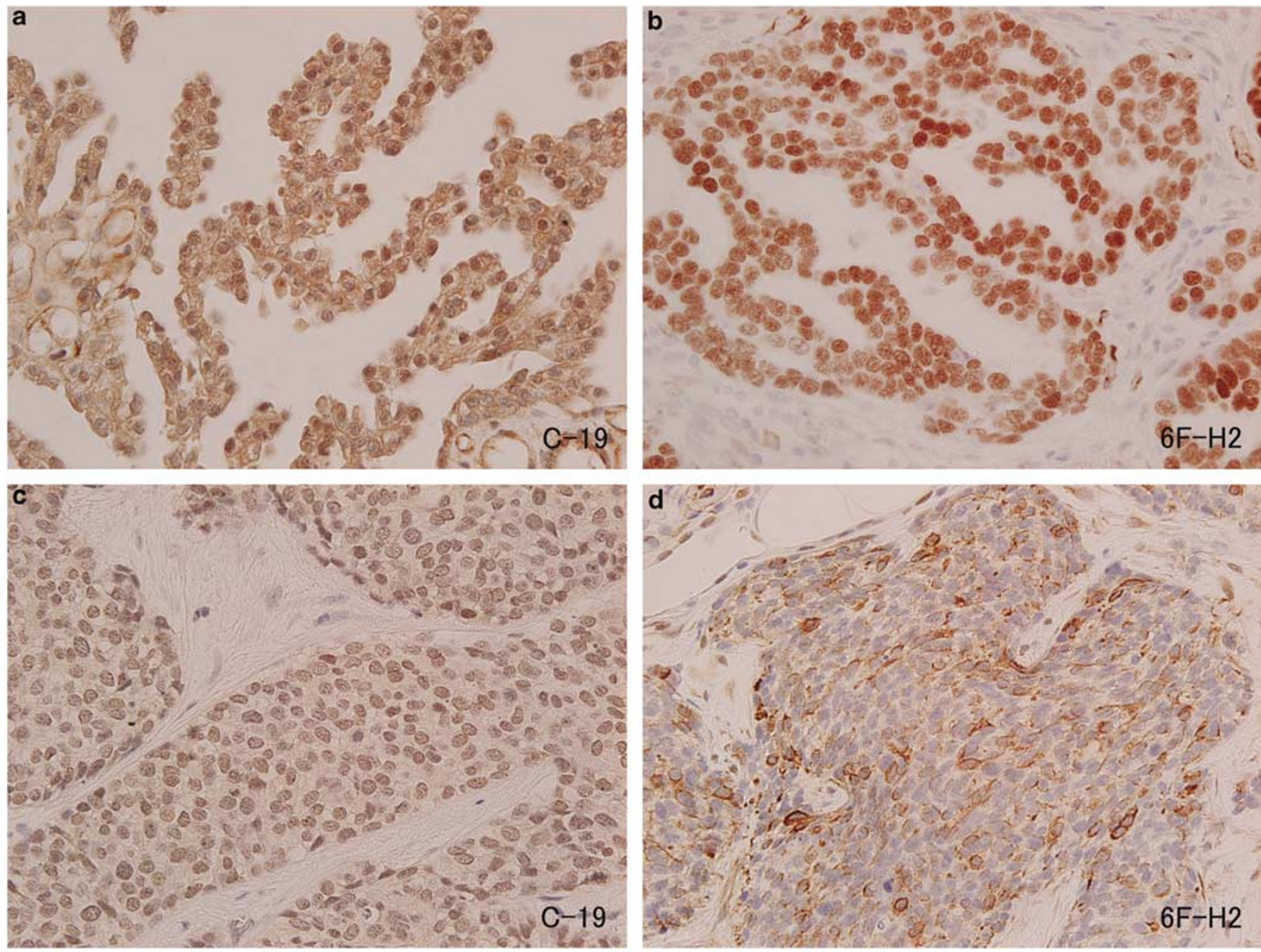

Figure 3 WT1 expression in ovarian serous adenocarcinoma (a, b) and desmoplastic small round cell tumor (c, d). Serous adenocarcinoma of the ovary showed nuclear and cytoplasmic staining for both antibodies (a, b). Desmoplastic small round cell tumor showed nuclear staining for C-19 (c), but also cytoplasmic staining for 6F-H2 in one of two cases (d). Original magnification $\times 400$.

of serous adenocarcinomas and sex cord stromal tumors of the ovary showed positive nuclear staining for C-19 and/or 6F-H2 (Figure 3). Both cases of desmoplastic small round cell tumor showed positive nuclear staining for C-19, and one of them also showed cytoplasmic staining for 6F-H2 (Figure 3). Nuclear staining was also found in a small number of the tumors from the stomach, lung, urinary tract, prostate, breast, endometrium, and soft tissue. Extremely strong cytoplasmic staining for $6 \mathrm{~F}-\mathrm{H} 2$ was observed in glioblastomas, some soft tissue sarcomas (clear cell sarcoma, leiomyosarcoma, malignant peripheral nerve sheath tumor, Ewing's sarcomas and rhabdomyosarcomas), osteosarcomas, and malignant melanomas of the skin as compared to other types of tumors (Figure 4). Most of these tumors showed a distinct diffuse or granular pattern of staining. One case of carcinosarcoma of the ovary showed nuclear staining in the epithelial element and cytoplasmic staining in the mesenchymal element for 6F-H2. Another case of carcinosarcoma of the uterus showed strong cytoplasmic staining exclusively in rhabdoid cells.
Immunohistochemistry using the immunoglobulin fraction of non-immune rabbit serum and mouse monoclonal immunoglobulin to fungal antigen as primary antibodies showed no positive staining in tumor cells.

Discrepancies in the immunohistochemical results obtained with polyclonal vs monoclonal antibodies were observed in 129 cases (38\%) (Table 3). Among 338 cases examined, $84(25 \%)$ were C-19 $(+) /$ $6 \mathrm{~F}-\mathrm{H} 2(-)$ and $45(13 \%)$ were C19 $(-) / 6 \mathrm{~F}-\mathrm{H} 2(+)$. The frequency of C-19 $(+) / 6 \mathrm{~F}-\mathrm{H} 2(-)$ was relatively high in lung cancers (21 of 43 cases) and cervical cancers (six of 13 cases), whereas that of C19 $(-) / 6 \mathrm{~F}$ $\mathrm{H} 2(+)$ was high in glioblastomas (six of 14 cases).

No significant difference in the rate of WT1 expression was found among the genders and age groups for each type of tumor (data not shown). There was no significant correlation between histologic or cytologic grade and WT1 staining for C-19 in any of the tumors. However, the positive rate for $6 \mathrm{~F}-\mathrm{H} 2$ was significantly lower in undifferentiated adenocarcinoma than differentiated adenocarcinoma of stomach (21 vs $65 \%, P=0.0032$ ) and colorectum 

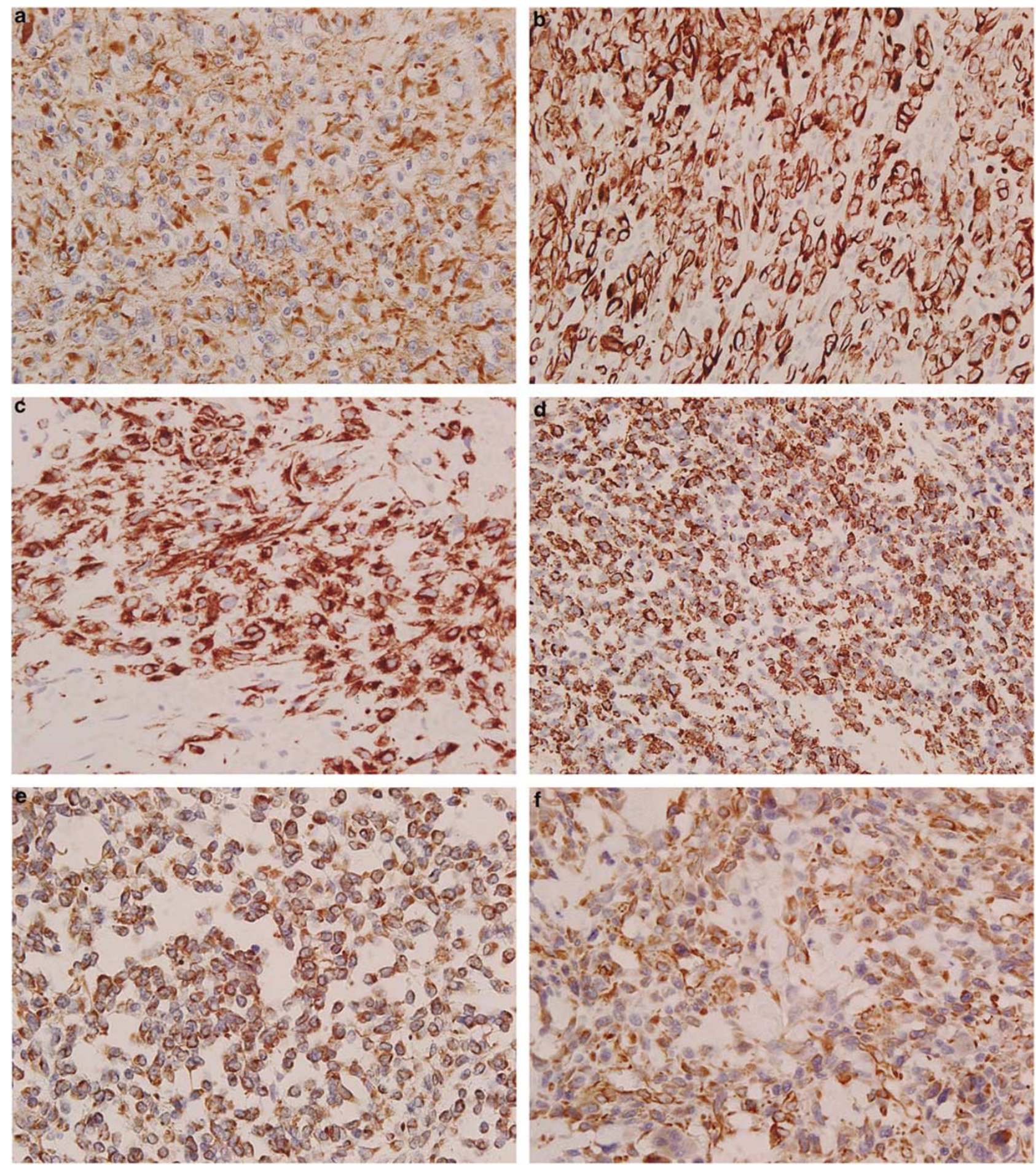

Figure 4 Glioblastoma (a), malignant melanoma of the skin (b), malignant peripheral nerve sheath tumor (c), rhabdomyosarcoma (d), Ewing's sarcoma (e), and osteosarcoma (f) showed extremely strong cytoplasmic staining. Original magnification $\times 400$.

(38 vs $76 \%, P=0.0487$ ). Urothelial carcinoma of grade 3 showed a significantly higher positive rate for $6 \mathrm{~F}-\mathrm{H} 2$ than did carcinomas of grades 1 and 2 (78 vs $20 \%, P=0.0027)$. No significant correlation was found between tumor stage and WT1 staining with either antibody in any kind of tumor.

\section{Western Blot Analysis}

To determine the subcellular distribution of WT1 protein in the lung cancer cells from clinical samples, cellular proteins were separated into nuclear and cytoplasmic fractions. Western blot 
Table 3 Correlation between immunohistochemical detection of WT1 using C-19 and 6F-H2

\begin{tabular}{lrcc}
\hline & \multicolumn{2}{c}{$6 \mathrm{~F}-\mathrm{H} 2$} & \multirow{2}{*}{ Total } \\
\cline { 2 - 3 } & Positive cases & Negative cases & \\
\hline C-19 & & & \\
Positive cases & 134 & 84 & 218 \\
Negative cases & 45 & 75 & 120 \\
Total & 179 & 159 & 338 \\
\hline
\end{tabular}

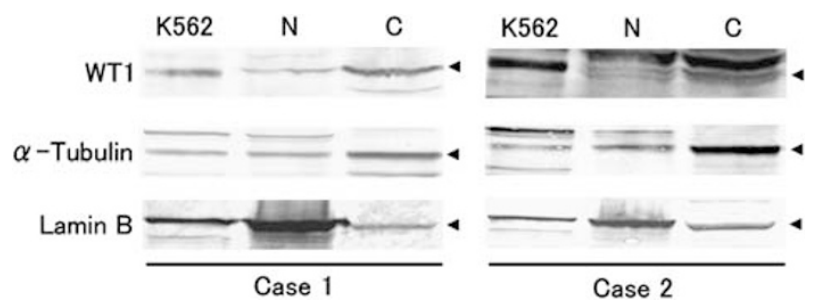

Figure 5 Western blot analysis revealed predominant intracytoplasmic expression of WT1 protein in lung cancer cells. N and C show the nuclear and cytoplasmic fractions of the tumor tissues, respectively. K562 shows whole cell lysate from leukemic cell line K562 which expresses WT1.

analysis revealed that WT1 protein was predominantly located in the cytoplasm (Figure 5).

\section{Discussion}

With the use of anti-WT1 polyclonal (C-19) and monoclonal (6F-H2) antibodies, positive staining in the tumor cells was observed in 35-100 and 5-88\% of the cases, respectively. The relatively high rates of positivity for WT1 in the present study contrast with some previous reports. Hwang et $a l^{21}$ reported that only a small number of breast cancers, and no colon cancers or lung cancers, expressed WT1. Ordonez et $a l^{17}$ also found that lung, breast, colon, and renal cancers did not express WT1. The discrepancy between our findings and previous results could be explained by the different criteria employed to judge WT1 positivity: they regarded nuclear but not cytoplasmic staining in the tumor cells as positive, because WT1 is principally a DNA binding transcription factor mainly distributed in the nucleus. In the present study, granular or diffuse cytoplasmic staining in the tumor cells was judged as positive, for reasons explained below.

The Western blot analysis revealed the intracytoplasmic localization of WT1 protein in the lung cancer cells. In addition, $\mathrm{we}^{30}$ and other investigators $^{31}$ showed the cytoplasmic expression of WT1 protein in cell lines derived from glioblastoma and lymphoma. Recent studies have revealed that phospholylation in the DNA-binding domain of WT1 alters the affinity for DNA and subcellular distribution of WT1. ${ }^{32}$ Post-translational phosphorylation at zinc fingers inhibits the ability to bind DNA, resulting in the cytoplasmic retention of WT1, and also inhibits transcriptional regulatory activity. Another study suggested that WT1 along with p53 can be sequestered in the cytoplasm of adenovirustransformed kidney cells. ${ }^{33}$ There is an interesting report that WT1 shuttles between the nucleus and cytoplasm and might be involved in the regulation of translation through its association with actively translating polysomes. ${ }^{27}$ Finally, particular kinds of tumors, such as glioblastomas, a subset of soft tissue sarcomas, osteosarcomas, and malignant melanomas of the skin frequently showed strong cytoplasmic staining, suggesting that WT1 may be involved in the development of these tumors. These findings are generally consistent with recent reports; Nakahara et $a l^{34}$ and Oji et $a l^{30}$ found that most glioblastomas showed cytoplasmic staining for WT1 and the overexpression of WT1 mRNA in the same glioblastoma tissues. Carpentieri et $a l^{19}$ and Sebire et $a l^{20}$ reported that all cases of rhabdomyosarcoma showed strong cytoplasmic staining.

The present immunohistochemical study revealed that WT1 is expressed in a wide variety of human malignancies, including those of the gastrointestinal and pancreatobiliary, urogenital and respiratory tracts, neuronal system and mesenchymal tissues. As far as we know, the present paper is the first report on the overexpression of WT1 in primary tumor tissues of the stomach, prostate, and biliary and urinary systems, and in malignant melanomas, newly adding these tumors to the list of WT1expressing cancers. Oji et al showed overexpression of WT1 mRNA in cell lines derived from various cancers and their primary tumors. ${ }^{22,24,30,35}$ They also demonstrated that the growth of WT1-expressing cancer cells was inhibited by treatment with WT1 antisense oligomers. ${ }^{13,14}$ These findings suggest that WT1 plays an important role in the carcinogenesis of various cancers.

The sensitivity of the staining for C-19 and 6F-H2 differed greatly between some kinds of tumors, that is, about half of all cases of lung cancer and cervical cancer showed C19 (+)/6F-H2 (-), while $43 \%$ of glioblastomas were C19 $(-) / 6 \mathrm{~F}-\mathrm{H} 2(+)$. The difference in immunoreactivity between $\mathrm{C}-19$ and $6 \mathrm{~F}-\mathrm{H} 2$ might be due to aberrant or dysregulated splicing and alterations of the WT1 gene. The WT1 gene encodes at least 24 isoforms produced by a combination of alternative splicing, RNA editing, and alternative usage of translation initiation sites. ${ }^{7}$ The initiation of translation at upstream or downstream of the original initiation site generates WT1 proteins extended or shortened at the $\mathrm{N}$ terminus, resulting in possible alteration of immunoreactivity to $6 \mathrm{~F}-\mathrm{H} 2$, which recognizes the $\mathrm{N}$ terminus of WT1. An aberrant transcript lacking the $\mathrm{N}$ terminal domain of WT1 in cell lines of prostate cancer, breast cancer, and leukemia were described. ${ }^{36}$ 
Previous reports showed that the level of WT1 mRNA correlated with tumor stage in testicular germ-cell tumors ${ }^{37}$ and head and neck squamous cell carcinomas, ${ }^{35}$ that is, higher levels in more advanced tumors. However, there was no correlation between WT1 expression and tumor stage in gastric and colorectal cancers in the present study (data not shown). To date, there has been no report showing the relationship between the expression of WT1 examined with immunohistochemistry and prognosis. Miyoshi et $a l^{15}$ reported that the disease-free survival rate was significantly lower in breast cancer patients with high levels of WT1 mRNA than those with low levels. Inoue et $a l^{10}$ showed that leukemia with strong WT1 mRNA expression showed a significantly lower rate of complete remission and significantly worse overall survival than that with weak expression.

WT1 could be a novel tumor rejection antigen in immunotherapy for various kinds of WT1-expressing cancers. WT1-specific cytotoxic T-lymphocytes induce the lysis of endogenously WT-1-expressing tumor cells in vitro, but do not damage physiologically normal WT1-expressing cells. It was shown that mice immunized with an MHC class I-restricted WT1 peptide rejected WT1-expressing tumor cells, whereas the cytotoxic T-lymphocytes did not affect normal healthy tissues. Clinical trials of WT1 peptide-based cancer immunotherapy showed that WT1 vaccination induced a reduction in tumor size or decrease in tumor marker levels in breast cancer, lung cancer, and leukemia. ${ }^{28,29}$ The results of the present study provide a rationale for immunotherapy targeting WT1 as a new treatment strategy for various kinds of tumors resistant to conventional surgery or chemoradiotherapy.

In conclusion, immunohistochemical study showed the cytoplasmic expression of WT1 in a large proportion of various kinds of human cancers. Immunohistochemical detection using routinely processed histologic sections could provide meaningful information on the expression of WT1 in cancer cells.

\section{Acknowledgements}

We thank Ms M Sugano and K Fujikawa (Osaka University Graduate School of Medicine), Mrs K Tanaka, Mr K Miyamoto, Y Fujita, and K Wakabayashi (Osaka Minami Medical Center) for technical assistance. We also thank Ms T Umeda, M Chatani, and S Watanabe (Osaka University Graduate School of Medicine) for assistance with inter-institutional communication.

\section{References}

1 Call KM, Glaser T, Ito CY, et al. Isolation and characterization of a zinc finger polypeptide gene at the human chromosome 11 Wilms' tumor locus. Cell 1990;60:509-520.
2 Gessler M, Poustka A, Cavenee W, et al. Homozygous deletion in Wilms tumours of a zinc-finger gene identified by chromosome jumping. Nature 1990; 343:774-778.

3 Pelletier J, Bruening W, Kashtan CE, et al. Germline mutations in the Wilms' tumor suppressor gene are associated with abnormal urogenital development in Denys-Drash syndrome. Cell 1991;67:437-447.

4 Pelletier J, Bruening W, Li FP, et al. WT1 mutations contribute to abnormal genital system development and hereditary Wilms' tumour. Nature 1991;353: 431-434.

5 Little MH, Prosser J, Condie A, et al. Zinc finger point mutations within the WT1 gene in Wilms tumor patients. Proc Natl Acad Sci USA 1992;89:47914795.

6 Tadokoro K, Fujii H, Ohshima A, et al. Intragenic homozygous deletion of the WT1 gene in Wilms' tumor. Oncogene 1992;7:1215-1221.

7 Scharnhorst V, van der Eb AJ, Jochemsen AG. WT1 proteins: functions in growth and differentiation. Gene 2001;273:141-161.

8 Haber DA, Englert C, Maheswaran S. Functional properties of WT1. Med Pediatr Oncol 1996;27: 453-455.

9 Pritchard-Jones K, Fleming S, Davidson D, et al. The candidate Wilms' tumour gene is involved in genitourinary development. Nature 1990;346:194-197.

10 Inoue K, Sugiyama H, Ogawa H, et al. WT1 as a new prognostic factor and a new marker for the detection of minimal residual disease in acute leukemia. Blood 1994;84:3071-3079.

11 Menssen HD, Renkl HJ, Rodeck U, et al. Presence of Wilms' tumor gene (wt1) transcripts and the WT1 nuclear protein in the majority of human acute leukemias. Leukemia 1995;9:1060-1067.

12 Inoue $\mathrm{K}$, Ogawa $\mathrm{H}$, Yamagami $\mathrm{T}$, et al. Long-term follow-up of minimal residual disease in leukemia patients by monitoring WT1 (Wilms tumor gene) expression levels. Blood 1996;88:2267-2278.

13 Oji Y, Ogawa H, Tamaki H, et al. Expression of the Wilms' tumor gene WT1 in solid tumors and its involvement in tumor cell growth. Jpn J Cancer Res 1999;90:194-204.

14 Yamagami T, Sugiyama H, Inoue $\mathrm{K}$, et al. Growth inhibition of human leukemic cells by WT1 (Wilms tumor gene) antisense oligodeoxynucleotides: implications for the involvement of WT1 in leukemogenesis. Blood 1996;87:2878-2884.

15 Miyoshi Y, Ando A, Egawa C, et al. High expression of Wilms' tumor suppressor gene predicts poor prognosis in breast cancer patients. Clin Cancer Res 2002; 8:1167-1171.

16 Amin KM, Litzky LA, Smythe WR, et al. Wilms' tumor 1 susceptibility (WT1) gene products are selectively expressed in malignant mesothelioma. Am J Pathol 1995;146:344-356.

17 Ordonez NG. Value of thyroid transcription factor-1, E-cadherin, BG8, WT1, and CD44S immunostaining in distinguishing epithelial pleural mesothelioma from pulmonary and nonpulmonary adenocarcinoma. Am J Surg Pathol 2000;24:598-606.

18 Foster MR, Johnson JE, Olson SJ, et al. Immunohistochemical analysis of nuclear vs cytoplasmic staining of WT1 in malignant mesotheliomas and primary pulmonary adenocarcinomas. Arch Pathol Lab Med 2001;125:1316-1320. 
19 Carpentieri DF, Nichols K, Chou PM, et al. The expression of WT1 in the differentiation of rhabdomyosarcoma from other pediatric small round blue cell tumors. Mod Pathol 2002;15:1080-1086.

20 Sebire NJ, Gibson S, Rampling D, et al. Immunohistochemical findings in embryonal small round cell tumors with molecular diagnostic confirmation. Appl Immunohistochem Mol Morphol 2005;13:1-5.

21 Hwang H, Quenneville L, Yaziji H, et al. Wilms tumor gene product: sensitive and contextually specific marker of serous carcinomas of ovarian surface epithelial origin. Appl Immunohistochem Mol Morphol 2004;12:122-126.

22 Oji Y, Miyoshi S, Maeda H, et al. Overexpression of the Wilms' tumor gene WT1 in de novo lung cancers. Int J Cancer 2002;100:297-303.

23 Silberstein GB, Van Horn K, Strickland P, et al. Altered expression of the WT1 Wilms tumor suppressor gene in human breast cancer. Proc Natl Acad Sci USA 1997;94:8132-8137.

24 Oji Y, Yamamoto H, Nomura M, et al. Overexpression of the Wilms' tumor gene WT1 in colorectal adenocarcinoma. Cancer Sci 2003;94:712-717.

25 Davies RC, Calvio C, Bratt E, et al. WT1 interacts with the splicing factor U2AF65 in an isoform-dependent manner and can be incorporated into spliceosomes. Genes Dev 1998;12:3217-3225.

26 Caricasole A, Duarte A, Larsson SH, et al. RNA binding by the Wilms tumor suppressor zinc finger proteins. Proc Natl Acad Sci USA 1996;93:7562-7566.

27 Niksic M, Slight J, Sanford JR, et al. The Wilms' tumour protein (WT1) shuttles between nucleus and cytoplasm and is present in functional polysomes. Hum Mol Genet 2004;13:463-471.

28 Oka Y, Tsuboi A, Murakami M, et al. Wilms tumor gene peptide-based immunotherapy for patients with overt leukemia from myelodysplastic syndrome (MDS) or MDS with myelofibrosis. Int J Hematol 2003;78:56-61.

29 Tsuboi A, Oka Y, Osaki T, et al. WT1 peptide-based immunotherapy for patients with lung cancer: report of two cases. Microbiol Immunol 2004;48:175-184.

30 Oji Y, Suzuki T, Nakano Y, et al. Overexpression of the Wilms' tumor gene WT1 in primary astrocytic tumors. Cancer Sci 2004;95:822-827.

31 Drakos E, Rassidakis GZ, Tsioli P, et al. Differential expression of WT1 gene product in non-Hodgkin lymphomas. Appl Immunohistochem Mol Morphol 2005;13:132-137.

32 Ye Y, Raychaudhuri B, Gurney A, et al. Regulation of WT1 by phospholylation: inhibition of DNA binding, alteration of transcriptional activity and cellular translocation. EMBO J 1996;15:5606-5615.

33 Maheswaran S, Englert C, Lee SB, et al. E1B 55K sequesters WT1 along with p53 within a cytoplasmic body in adenovirus-transformed kidney cells. Oncogene 1998;16:2041-2050.

34 Nakahara Y, Okamoto H, Mineta T, et al. Expression of the Wilms' tumor gene product WT1 in glioblastomas and medulloblastomas. Brain Tumor Pathol 2004;21: 113-116.

35 Oji Y, Inohara H, Nakazawa M, et al. Overexpression of the Wilms' tumor gene WT1 in head and neck squamous cell carcinoma. Cancer Sci 2003;94:523529.

36 Dechsukhum C, Ware JL, Ferreira-Gonzalez A, et al. Detection of a novel truncated WT1 transcript in human neoplasia. Mol Diagn 2000;5:117-128.

37 Harada Y, Nonomura N, Nishimura K, et al. WT1 gene expression in human testicular germ-cell tumors. Mol Urol 1999;3:357-364. 